\title{
ASSESSMENT OF POSSIBLE IN-SITU FORMATION OF HYDRATE DURING GAS PRODUCTION FOR THE CONDITIONS OF THE GAS FIELD YUZNO-RUSSKOE
}

\author{
• . ус к ев, . - ородин, • • с нов \\ N. G. Musakaev, S. L. Borodin, M. K. Khasanov
юменский фили л нститут теоретической и прикл дной мех ники им. . . ристи нович , г. юмень
юменский индустри льный университет, г. юмень
терлит м кский фили $л$ шкирского госуд рственного университет, г. терлит м к
лючевые слов : гидр тообр зов ние; приз бойн язон скв жины; м тем тическ ямодель Key words: hydrate formation; bottomhole zone; mathematical model

н стоящее время осушествляется промышленное освоение н дсеном нских (турон-сеноских) месторождений дым- ур- зовского г зодобыв ющего регион , p сположенного н севере п дной ибири [1]. ля д нного регион х p ктерно н личие толщи многолетней мерзлоты, поэтому темпер тур г зосодерж щих пород ок зыв ется довольно низкой, неизбежное ее понижение при добыче г 3 приводит к созд нию условий, которые бл гоприятствуют обр зов нию гидр тов природного г з либо непосредственно в приз бойной зоне г зоносных пл стов, либо в стволе г зовых скв жин $[2,3]$. роме низких пл стовых темпер тур термодин мическими особенностями жно- усского г зового месторождения являются ном льно высокие пл стовые д вления и низк я минер лиз ция поровой вл ги, что т кже определяет возможность обр зов ния г зовых гидр тов к к в пл сте, т к и в систем х подземного и н земного оборудов ния этого месторождения. ким обр зом, н дсеном нские з лежи д нного месторождения могут относиться к Г з-г зогидр тным з леж м либо н ходиться в предгидр тном термодин мическом состоянии [1]. ля жно- усского г зового месторождения в приз бойной зоне скв жины возможно гидр тообр зов ние уже при р бочих депрессиях н пл ст, т кже при г зодин мических исследов ниях скв жин (рис. 1).


ля р зр ботки мероприятий по предупреждению гидр тообр зов ния в пористой среде необходим теоретическ я прор ботк ук з нной проблемы, котор я позволит в зн чительной мере уменьшить объем необходимых эксперимент льных 
и промысловых д нных и выбр ть оптим льные условия для их ре лиз ции, предст вление о сути изуч емых процессов д ет возможность непосредственного упр вления ими [4].

ценку возможности обр зов ния г зового гидр т в пористой среде при отборе природного г 3 из з лежи огр ниченных р змеров проведем н примере модельной осесимметричной з д чи о притоке г 3 к совершенной скв жине в горизонт льном пл сте, кровля и подошв которого непрониц емы. риним я пл ст однородным и изотропным, т кже пренебрег я влиянием верхней и нижней гр ниц, можно счит ть, что $з$ д ч одномерн я, и п р метры з висят только от р дильной координ ты и времени (рис. 2) [5].

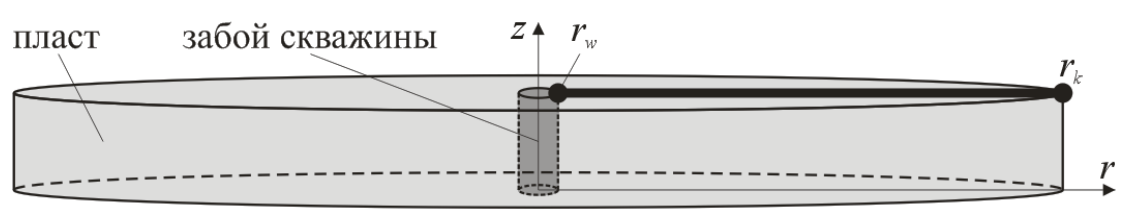

ис. 2. хем обл сти моделиров ния

родуктивный пл ст 3 полнен в исходном состоянии г зом и водой, д вление $p_{0}$ и темпер тур $T_{0}$ которых соответствуют термодин мическим условиям существов ния их в свободном состоянии:

$$
t=0, r_{w}<r<r_{k}: T=T_{0}, p=p_{0}, S_{h}=0, S_{l}=S_{l 0}, S_{g}=1-S_{l 0} .
$$

десь и д лее нижние индексы $s k, h, l$ и $g$ относятся к п р метр м скелет , гидр т , воды и г з соответственно; $t-$ время; $r-\mathrm{p}$ ди льн я координ т $; r_{w}-\mathrm{p}$ диус скв жины; $r_{k}-\mathrm{p}$ диус контур пит ния; $S_{j}(j=g, l, h)-$ н сышенность пор $j$-й фзй; $S_{l 0}-$ н ч льн я водон сыщенность.

усть через скв жину, вскрывшую пл ст н всю толщину, отбир ется г 3 при постоянном з бойном д влении $p_{w}$ :

$$
t>0, r=r_{w}: \quad p=p_{w}<p_{0}, \quad \frac{\partial T}{\partial r}=0 .
$$

пр вой гр нице пл ст $з$ пишем условия по темпер туре и д влению:

$$
t>0, r=r_{k}: \frac{\partial p}{\partial r}=0, \quad \frac{\partial T}{\partial r}=0 .
$$

римем следующие допущения. идр т является двухкомпонентной системой с м ссовой концентр цией г $3 G$. емпер туры г 3 , жидкости, гидр т и пористой среды в к ждой точке пл ст совп д ют (однотемпер турн я модель). оложим, что пористость пл ст $m$ постоянн , скелет пористой среды, г зовый гидр т и вод несжим емы и неподвижны $[5,6]$.

ри сдел нных допущениях ур внения, описыв ющие 3 д чу о притоке г 3 к скв жине, могут быть 3 пис ны в виде [6-10]:

$$
\begin{gathered}
m \frac{\partial}{\partial t}\left(\rho_{g} S_{g}\right)+m \frac{1}{r} \frac{\partial}{\partial r}\left(r \rho_{g} S_{g} v_{g}\right)=-G m \rho_{h} \frac{\partial S_{h}}{\partial t}, \\
m \rho_{l} \frac{\partial S_{l}}{\partial t}=-(1-G) m \rho_{h} \frac{\partial S_{h}}{\partial t},
\end{gathered}
$$




$$
\begin{gathered}
m S_{g} v_{g}=-\frac{k_{g}}{\mu_{g}} \frac{\partial p}{\partial r}, \\
\rho c \frac{\partial T}{\partial t}+m S_{g} \rho_{g} c_{g} v_{g} \frac{\partial T}{\partial r}=\frac{1}{r} \frac{\partial}{\partial r}\left(r \lambda \frac{\partial T}{\partial r}\right)-m S_{g} \rho_{g} c_{g} v_{g} \varepsilon \frac{\partial p}{\partial r}+m S_{g} \rho_{g} c_{g} \eta \frac{\partial p}{\partial t}+m \rho_{h} L_{h} \frac{\partial S_{h}}{\partial t}, \\
p=z_{g} \rho_{g} R_{\mathrm{g}} T, \quad z_{g}=\left(0,17376 \cdot \ln \left(\frac{T}{T_{c}}\right)+0,73\right)^{p / p_{c}}+\frac{0,1 p}{p_{c}}, \\
\rho c=(1-m) \rho_{s k} c_{s k}+m \sum_{j=g, l, h} \rho_{j} S_{j} c_{j}, \quad \lambda=(1-m) \lambda_{s k}+m \sum_{j=g, l, h} S_{j} \lambda_{j}, \\
\varepsilon_{i}=-\frac{1}{\rho_{g} c_{g}} \frac{T}{z_{g}}\left(\frac{\partial z_{g}}{\partial T}\right)_{p}, \quad \eta_{s}=\frac{1}{\rho_{g} c_{g}}-\varepsilon_{i},
\end{gathered}
$$

где $p$ и $T$ - д вление и темпер тур фильтр ционного поток ; $\rho_{j}(j=s k, h, l$ и $g)-$ истинн я плотность $j$-й ф зы; $v_{g}, k_{g}$ и $\mu_{g}-$ скорость, прониц емость и дин мическ я вязкость г з; $c_{j}$ и $\lambda_{j}(j=s k, g, l, h)$ - удельн я теплоемкость и коэффициент теплопроводности $j$-й ф зы; $\varepsilon-$ коэффициент жоуля - омсон (дифференцильный коэффициент дросселиров ния); $\eta$ - коэффициент ди 6 тического охл ждения; $R_{g}-$ г зов я постоянн я; $z_{g}-$ коэффициент сжим емости г $3 ; L_{h}-$ удельн я теплот гидр тообр зов ния; $T_{c}$ и $P_{c}$ - эмпирические п р метры.

к к к фильтруется только г з, то основной вкл д в величины $\rho c$ и $\lambda$ вносят п р метры скелет пористой среды [9, 11]. ействительно, оценки пок зыв ют, что если н ч льн я водон сыщенность пл ст р вн 0,5 , его пористость $\mathrm{p}$ вн 0,1 , то при полном переходе воды в гидр т удельн я объемн я теплоемкость системы уменьшится примерно н $4 \%$, коэффициент теплопроводности системы увеличится н $5 \%$. оэтому во всем пл сте величины $\rho c$ и $\lambda$ можно пол г ть постоянными.

p боте использов н следующий подход к прогнозу возможного обр зов ния гидр тов при отборе г 3 [3]: из решения з д чи неизотермической фильтр ции несовершенного г 3 н ходятся р спределения д вления и темпер туры в пл сте, которые з тем ср внив ются с р вновесными условиями обр зов ния гидр тов в приз бойной зоне скв жины (см. рис. 1). кже отметим, что поскольку основной изуч емой проблемой является оценк возможности выполнения термодин мических условий обр зов ния гидр т в приз бойной зоне скв жины и/или продуктивном пл сте при добыче г з, то ур внение (4) будем р ссм трив ть без последнего сл г емого, связ нного с ф зовыми переход ми.

истемы ур внений (1)-(5) с 3 д нными н ч льными и гр ничными условиями решены численно, при этом использов ны неявн я р зностн я схем, метод прогонки и метод простых итер ций $[8,12]$. л год ря использов нию бсолютно устойчивой неявной схемы, можно бр ть большие временные ш ги, что приводит к зн чительному уменьшению времени р счетов.

р счет х приним лись следующие зн чения п р метров: $p_{0}=10$; $p_{w}=8 \quad ; T_{0}=286,7 \quad\left(13,6{ }^{0} \mathrm{C}\right) ; r_{w}=0,1 \mathrm{~m} ; r_{k}=500 \mathrm{M} ; m=0,3 ; k_{g}=510^{-14} \mathrm{M}^{2} ;$ $\left.\left.S_{l 0}=0,1 ; p_{c}=4,6 \quad ; T_{c}=190,6 ; c_{s k}=1000 \mathrm{~W} /(\mathrm{K \Gamma})\right) ; c_{l}=4200 \mathrm{~W} /(\mathrm{K \Gamma})\right) ;$ $\lambda_{s k}=1,5 \mathrm{~T} /(\mathrm{M}) ; \quad \lambda_{l}=0,56 \quad \mathrm{~T} /(\mathrm{M}) ; \quad R_{g}=518 \quad$ Ж $/(\mathrm{K \Gamma} \quad) ; \quad \rho_{s k}=2000 \mathrm{K \Gamma} / \mathrm{M}^{3} ;$ $\rho_{l}=1000 \mathrm{K \Gamma} / \mathrm{M}^{3}$.

волюция во времени темпер туры г з непосредственно н 3 бое скв жины (время эксплу т ции скв жины сост вляет один год) в 3 висимости от з бойного д вления приведен н рис. 3 (н этом и последующих рисунк х штрихов я линия 
- это р вновесн я темпер тур гидр тообр зов ния, соответствующ я з бойному д влению). чевидно, что более низкому зн чению з бойного д вления (соответственно большей депрессии н пл ст) соответствует более сильное охл ждение приз бойной зоны вследствие действия дроссельного эффект и эффект ди б тического охл ждения.

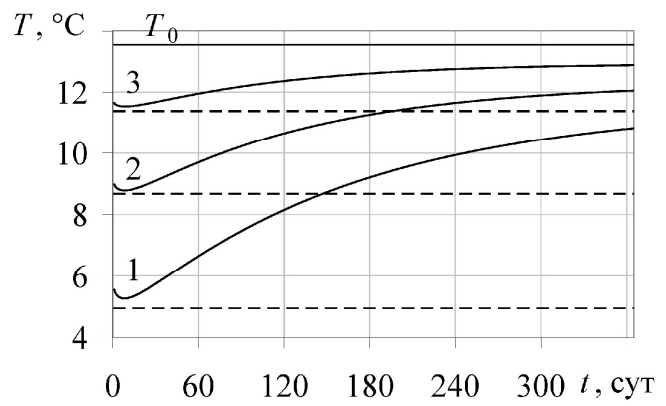

ис. 3. зменение во времени темпер туры в сечении, примык ющемукскв жине, при р зличных зн чениях 3 бойного д вления $p w$ : линии 1, 2 и 3 соответствуют $p w=4,6 u 8$

ожно ожид ть, что при к ком-то зн чении д вления н з бое скв жины темпер тур в пл сте уп дет ниже р вновесной темпер туры гидр тообр зов ния $T_{s}(p)$. дн ко, к к следует из рис. 3, для принятых в $\mathrm{p}$ боте зн чений п р метров этого не происходит, что связ но с соответствующим снижением величины $T_{s}(p)$ при уменьшении д вления (см. рис. 1). кже из рис. 3 видно, что построенные 3 висимости имеют немонотонный х р ктер: темпер тур вн ч ле пониж ется, 3 тем н чин ет восст н влив ться. ремя н ступления минимум темпер туры н 3 бое пр ктически не 3 висит от величины з бойного д вления (в р боте это время сост вляет 8-9 суток).

ремя достижения миним льного зн чения темпер туры в сечении, примык ющему к скв жине, существенным обр зом 3 висит от прониц емости $k_{g}$ (рис. 4).

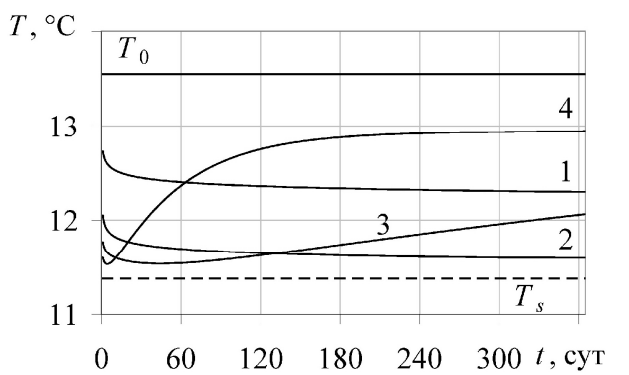

ис. 4. волюция во времени темпер туры в сечении, примык ющемук скв жине, при р зличных зн чениях прониц емости пл ст по г зу $\mathrm{kg}$ : линии 1, 2, 3 и 4 соответствуют $k g=10-16,10-15,10-14$ и $10-13 \mathrm{~m}^{2}$

пример, при прониц емости $k_{g}=10^{-13} \mathrm{M}^{2}$ миним льное зн чение темпер туры достиг ется 34 сут, при прониц емости $10^{-14} \mathrm{M}^{2}-$ примерно 3 полтор месяц (для более низких прониц емостей д нный минимум не н ступил 3 р счетные 365 суток). о есть чем ниже прониц емость пл ст , тем дольше ск зыв ется действие дроссельного эффект и эффект ди б тического охл ждения. ри этом, к к видно из рис. 4, величин миним льного зн чения темпер туры пр ктически не $з$ висит от прониц емости, н пример при прониц емости $10^{-13} \mathrm{M}^{2}$ минимум сост вляет $11,53{ }^{0} \mathrm{C}$, при $k_{g}=10^{-14} \mathrm{M}^{2}-11,54{ }^{0} \mathrm{C}$.

рис. 5 предст влен эволюция во времени темпер туры г 3 непосредственно н 3 бое скв жины в 3 висимости от пористости пл ст. идно, что при больших зн чениях пористости пл ст в приз бойной зоне темпер тур сниж ется ниже р вновесной (линия 4). то может быть связ но с более возр ст ющим вкл дом эффект ди 6 тического охл ждения в уменьшение темпер туры. овидимому, другой причиной т кой з висимости является уменьшение общей объ- 
емной теплоемкости н сыщенной пористой среды при увеличении пористости.

кже стоит отметить, что при больших зн чениях пористости допущение о неподвижности воды может ок $з$ ться весьм сильным.

\author{
ис. 5. зменение во времени \\ темпер турь \\ в сечении, примык ющему кскв жине, \\ при р зличных зн чениях \\ пористости пл $\mathrm{cm}$ \\ (линии 1, 2, 3 и 4 соответствуют \\ $m=0,1 ; 0,3 ; 0,4$ u 0,5$)$
}

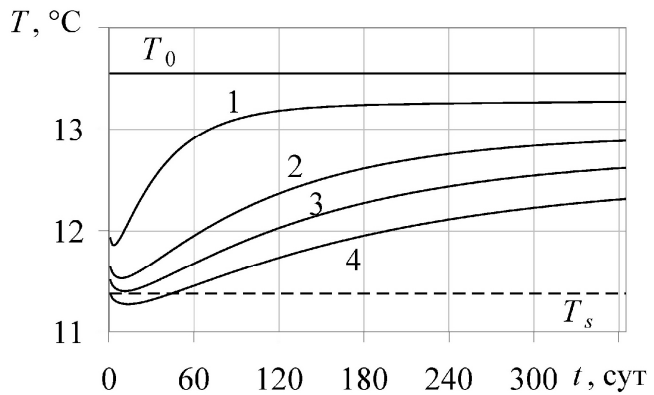

ким обр зом, проведено м тем тическое моделиров ние, и построен численн я схем , позволяющ я н йти основные п р метры фильтр ционного течения при добыче г $з$ для условий жно- усского г зового месторождения. роведен н лиз влияния з бойного д вления и п р метров пористой среды н $\mathrm{p}$ спределения темпер туры и д вления в пл сте, термоб рические п р метры которого близки к р вновесной кривой гидр тообр зов ния. оК з но, что з висимости от времени темпер туры г 3 н 3 бое скв жины при р зличных зн чениях 3 бойного д вления имеют немонотонный х р ктер. тмечено, что время достижения темпеp турой н 3 бое своего минимум пр ктически не 3 висит от величины з бойного д вления, но существенным обр зом з висит от прониц емости пл ст .

писок литер туры
1. стомин . ., едулов . . ермодин мик обр зов ния г зовых гидр тов в приз бойной зоне г зовых и г зоконденс тных скв жин // тери лы оссийской конференции « зовые гидр ты в экосистеме емли' 2014». овосибирск, 7-10 преля 2014. - . 32-33.

2. ргунов ., онд рев . ., ожин . . лияние неизотермических эффектов н добычу г 3 в северных р йон х с учетом возможного гидр тообр зов ния в приз бойной зоне скв жин // естник овосибирского госуд рственного университет . ерия: м тем тик , мех ник, информ тик . $-2012 .-$. 12. - ып. 4. - .9-15.

3. ожин . . ермодин мические эффекты в м тем тических моделях добычи природного г 3 в северных регион х: диссерт ция н соиск ние уч. степ. доктор техн. н ук. - овосибирск, 2015. - 264 с.

4. ернов . . оделиров ние нер вновесных процессов крист ллиз ции, к вит ции и гидр тообр зов ния в мет ст бильных сред х: вторефер т диссерт ции н соиск ние уч. степ. доктор физ.-м т. н ук. - овосибирск, 2012. $-43 \mathrm{c}$.

5. сниев . ., очин . ., ксимов . . одземн я гидромех ник . - . едр , 1993. -416 с.

6. ус к ев. ., с нов. тем тическое моделиров ние процесс добычи г з из г зогидр тной 3 лежи с учетом обр зов ния льд // естник юменского госуд рственного университет . изико-м тем тическое моделиров ние. ефть, г з, энергетик . - 2014. - № 7. - . 43-50.

7. ек люк . . ермодин мик нефтяного пл ст . - $\therefore$ едр , 1965. -238 с.

8. ус к ев ородин ценк возможности гидр тообр зов ния в пл сте при добыче г з : м тери лы междун родной н учно-технической конференции « ефть и г 3 п дной ибири», посвященной 90-летию со дня рождения . . осухин , юмень, 15-16 октября 2015. - юмень: зд-во юм , 2015. - . II. - . 284-290.

9. Shagapov V. Sh., Musakaev N. G., Khasanov M. K. Formation of gas hydrates in a porous medium during an injection of cold gas // Int. J. of Heat and Mass Transfer. - 2015. - Vol.84. - P.1030-1039.

10. тонов . ., уревич . . счет коэффициент сжим емости природного г з // зов я промышленность. -1969 . - № 2. - С. 7-9.

11. с нов. ., ус к ев.., им лтдинов . . собенности диссоци ции г зогидр тов с обр зов нием льд в пористой среде // нженерно-физический журн л. - 2015. - . 88. - № 5. - . 1022-1030.

12. ус к ев.., ородин .., ом нюк.. етоды решения одномерной р ди льной з д чи теплоперед чи в окруж ющие скв жину мерзлые породы // естник юменского госуд рственного университет . изиком тем тическое моделиров ние. ефть, г з, энергетик . - 2014. - № 7. - . 19-26.

ведения об втор $x$

ускев иль бс лямович, д. ф.-м. н., профессор к федры « зр ботк и эксплу т иия нефтяных и г зовых месторождений», юменский индустри льный университет; з ведующий л бор торией юменского фили $л$ нститут теоретической $и$ прикл дной мех ники им. ристи нович , г. юмень, тел. 8(3452)682745,e-mail:timms@tmn.ru
Information about the authors

Musakaev N. G., Doctor of Physics and Mathematics, professor of the chair "Development and operation of oil and gas fields», Industrial University of Tyumen; head of the laboratory at Tymen Branch of the Institute of Theoretical and Applied Mechanics named after Christianovich S. A., phone: 8(3452) 682745,e-mail:timms@tmn.ru 
ородин т нисл в еонидович, к. ф.-м. н., н учный сотрудник, юменский фили л нститут теоретической и прикл дной мех ники им. . . ристи нович , 2. юмень, mел.: 8(3452)682745, e-mail: timms@tmn.ru

с нов p m милович, к. ф.-м. н., доцент к федры прикл дной м тем тики и мех ники, терлит м кский фили $л$ шкирского госуд рственного университет, еспублик

шкортост $\mathrm{H}, \quad$ 2. терлит $\mathrm{M} \kappa$ 8(3473)431056, e-mail: hasanovmk@mail.ru
Borodin S. L., Candidate of Science in Physics and Mathematics, scientific worker of Tymen Branch of the Institute of Theoretical and Applied Mechanics named after Christianovich S. A., phone: 8(3452) 682745, e-mail: timms@tmn.ru

Khasanov M. K., Candidate of Science in Physics and Mathematics, associate professor of the chair «Applied mathematics and mechanics» at Sterlitamak Branch of Bashkir State University, the Rpublic of Bashkortostan, phone: 8(3473)431056, e-mail: hasanovmk@mail.ru 